\title{
Discharging coronavirus disease 2019 (COVID-19) patients with faecal viral shedding and prolonged hospitalisation
}

Jaime S. Rosa Duque ${ }^{1}$, Phoebe Q. Mak ${ }^{2}$, Joshua S.C. Wong ${ }^{2}$, Chi-man Victor Chan ${ }^{3}$, Chit Kwong Chow ${ }^{4}$, Wa Keung Chiu $^{4}$, Wilson K.Y. Yeung ${ }^{3}$, Ivan C.S. Lam², Gilbert T. Chua ${ }^{1}$, Marco H.K. Ho ${ }^{1}$, Kelvin K.W. To ${ }^{5}$, Patrick Ip ${ }^{1}$, Mike Y.W. Kwan*2

${ }^{1}$ Department of Paediatrics and Adolescent Medicine, Queen Mary Hospital, Li Ka Shing Faculty of Medicine, The University of Hong Kong, Hong Kong Special Administrative Region, China

${ }^{2}$ Department of Paediatrics and Adolescent Medicine, Princess Margaret Hospital, Hong Kong Special Administrative Region, China

${ }^{3}$ Department of Paediatrics and Adolescent Medicine, Pamela Youde Nethersole Eastern Hospital, Hong Kong Special Administrative Region, China

${ }^{4}$ Department of Paediatrics and Adolescent Medicine, United Christian Hospital, Hong Kong Special Administrative Region, China

${ }^{5}$ Department of Microbiology, Queen Mary Hospital, Li Ka Shing Faculty of Medicine, The University of Hong Kong, Hong Kong Special Administrative Region, China

Received: August 24, 2020

DOI: $10.5430 /$ jha.v9n5p26
Accepted: October 11, 2020

Online Published: October 28, 2020

\begin{abstract}
The implication of gastrointestinal infection caused by the severe acute respiratory syndrome coronavirus 2 (SARS-CoV-2) and its transmission remains to be fully understood. We studied 4 paediatric patients with several weeks of faecal excretion of SARS-CoV-2 RNA who had only mild symptoms. International consensus on isolation practices is urgently needed.
\end{abstract}

Key Words: Hospitalisation, Isolation, SARS-CoV-2, COVID-19, Stool

\section{INTRODUCTION}

Since the severe acute respiratory syndrome coronavirus 2 (SARS-CoV-2) became known to cause the highly contagious coronavirus disease 2019 (COVID-19), the World Health Organization (WHO) declared this infection a pandemic on 11 March 2020. ${ }^{[1]}$ Many governments implemented stringent policies such as lockdown of cities, social distancing restrictions, quarantine requirements for travellers and isolation of patients. Nevertheless, these containment strategies were unable to avert its rapid spread across the world. As such, this deadly virus has led to over 7 million reported cases and 400,000 deaths globally within a half year. ${ }^{[2]}$ The COVID-19 can cause sinopulmonary, cardiovascular, neurological, cutaneous and gastrointestinal illnesses, paediatric multisystem inflammatory syndrome in children, or an individual may be an asymptomatic carrier. ${ }^{[3]}$

\footnotetext{
*Correspondence: Mike Y.W. Kwan; Email: mikekwanyw@gmail.com; Address: Department of Paediatrics and Adolescent Medicine, Princess Margaret Hospital, Hong Kong Special Administrative Region, China. 
SARS-CoV-2 enters cells via interaction between the SARS$\mathrm{CoV}-2$ spike protein receptor-binding domain (RBD) and the host cell receptor, angiotensin-converting enzyme 2 (ACE2). SARS-CoV-2 has been shown to replicate in human intestinal organoid. ${ }^{[4]}$ Viral particles can be detected from enteric tracts of affected patients who experience nausea, vomiting, abdominal pain, diarrhoea, or individuals may have no gastrointestinal symptoms at all. ${ }^{[5,6]}$ Gastrointestinal infection or colonisation, evident by detection of SARS-CoV-2 RNA, may occur for $>4$ weeks and may last longer than in the respiratory system. ${ }^{[7,8]}$ Here we studied the clinical manifestations, timeline and outcomes of 4 paediatric patients in Hong Kong (HK) who demonstrated faecal viral shedding of SARS-CoV-2.

\section{Summary OF CASES}

\subsection{Patient 1}

A 16-year-old Chinese boy with attention-deficit/hyperactivity disorder and allergic rhinitis (AR) lived in London, United
Kingdom (UK) as a student. He returned to HK and was admitted due to sore throat, chest pain and cough for 3 days. Nasopharyngeal aspirate (NPA), throat swab (TS) and stool were positive for SARS-CoV-2 by reverse transcriptasepolymerase chain reaction (RT-PCR). Chest $\mathrm{x}$-ray revealed bilateral perihilar infiltrates, and he had elevated troponin I up to $98.4(<21 \mathrm{ng} / \mathrm{L})$ but normal creatine kinase, lactate dehydrogenase and electrocardiogram tracings. After temporary discontinuation of his methylphenidate, the troponin I decreased to $41.4 \mathrm{ng} / \mathrm{L}$, and he suffered no cardiac complications. SARS-CoV-2 was persistently detected in his nasopharyngeal swabs NPS/TS and stool, but he only had occasional loose stools. He received 7 days of amoxicillinclavulanate and 3 days of azithromycin, and subsequently, his pneumonia resolved. SARS-CoV-2 from his NPS/TS and stool became negative for 2 consecutive days on days 38 and 42 , respectively, and he was allowed off isolation (see Figure 1). Anti-SARS-CoV-2-receptor-binding-domain (RBD) and anti-SARS-CoV-2-nucleocapsid (NP) IgGs were detectable on day 45.

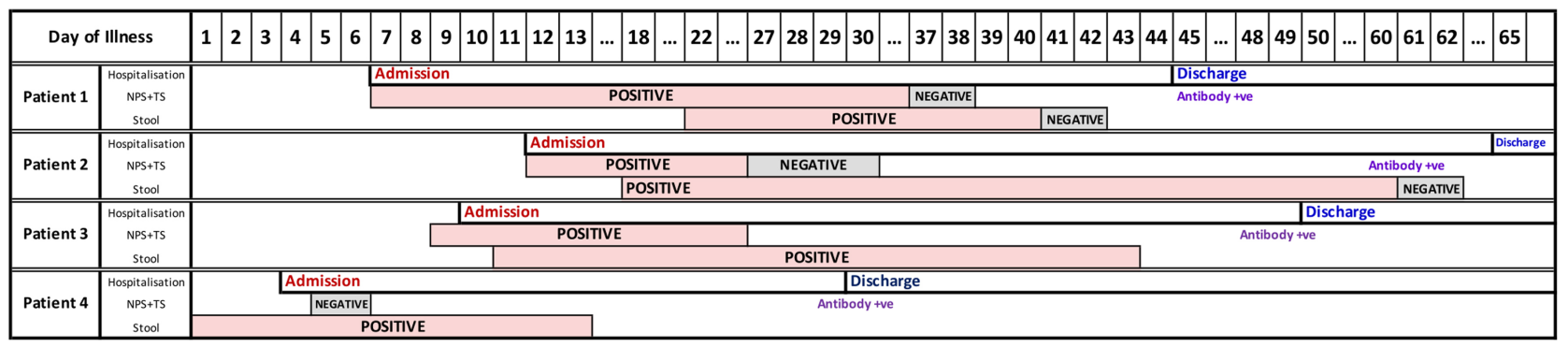

NPS+TS = pooled nasopharyngeal and throat swab (for SARS-COV-2 RT-PCR)

Stool = stool sample for SARS-COV-2 RT-PCR

Antibody $+v e=$ anti-SARS-COV-2-receptor-binding-domain Ig G and anti-SARS-COV-2-nucleoprotein Ig G positive

Figure 1. Timeline of SARS-CoV-2 detection in respriatory and stool samples

Timeline of hospital admission, discharge and SARS-CoV-2 detection by reverse transcriptase-polymerase chain reaction (RT-PCR) via pooled nasopharyngeal and throat swab (NPS/TS) and stool sampling. For patient 1, SARS-CoV-2 from NPS/TS and stool results became negative for 2 consecutive days on days 38 and 42, respectively. Anti-SARS-CoV-2-receptor-binding-domain (RBD) and anti-SARS-CoV-2-nucleocapsid (NP) IgGs were detectable on day 45. For patient 2, SARS-CoV-2 remained detectable via NPS/TS (day 23, negative on days 27 and 30) and stool (day 60). He had 2 consecutive days with negative RT-PCR results from the stool on days 61 and 62. Patient 3 was allowed to return home based on updated hospital discharge criteria made by the HK Government in May 2020, with measurable anti-SARS-CoV-2-RBD IgG on day 48. SARS-CoV-2 RNAs remained detectable via NPS/TS sampling on day 24 and stool on day 43, which were not retested. SARS-CoV-2 RNAs of patient 4 remained persistently detectable from her stool, with the most recent on day 13, which was not retested. She was discharged after testing positive with anti-SARS-CoV-2-RBD IgG on day 29. NPS/TS, pooled nasopharyngeal and throat swab for SARS-CoV-2 RT-PCR; stool, stool sampling for SARS-CoV-2 RT-PCR; antibody +ve, detectable anti-SARS-CoV-2-RBD IgG

\subsection{Patient 2}

A 16-month-old Chinese boy with glucose-6-phosphate dehydrogenase deficiency, cow's milk and egg allergies and AR resided in London, UK. When he returned to HK, he was tested SARS-CoV-2 positive via NPS/TS and rectal swab by RT-PCR after his parents developed febrile COVID-19 illnesses. Although he remained mostly asymptomatic through- out hospitalisation, SARS-CoV-2 remained detectable via NPS/TS until day 23 (negative on days 27 and 30) and stool until day 60, after which he was discharged (see Figure 1). Anti-SARS-CoV-2-RBD and anti-SARS-CoV-2-NP IgGs were detectable on day 60 . His father, who also tested SARSCoV-2 positive by NPS/TS but turned negative by days 30 and 31 , remained with him under inpatient isolation for 2 
months as he felt the need to provide parental care for this young toddler.

\subsection{Patient 3}

A 17-year-old boy with AR and exophoria who travelled to Edinburgh, UK for 2 months initially tested negative for SARS-CoV-2 RT-PCR via NPS/TS by the HK surveillance program upon his arrival. Ten days later, he presented with 9 days of headache, rhinorrhoea, sore throat, abdominal pain and loose stools with detectable SARS-CoV-2 sampled from his NPS/TS and stool. These remained positive throughout his hospitalisation even when his symptoms resolved a few days afterwards. However, due to updated discharge criteria made by the HK Government in May 2020, the patient was allowed off isolation on day 48 with $>10$ days stable condition under inpatient observation and measurable antiSARS-CoV-2-RBD IgG (see Figure 1). ${ }^{[9]}$ The serum level of his anti-SARS-CoV-2-NP IgG was reported as equivocal. SARS-CoV-2 remained detectable by NPS/TS 3 weeks and stool 7 days (day 43) prior to hospital discharge, which was not retested.

\subsection{Patient 4}

A 14-month-old girl who returned from a trip to the UK was found to have SARS-CoV-2 in her stool from the surveillance program upon arrival to HK. She remained mostly asymptomatic but remained hospitalised while SARS-CoV-2 was persistently detected in her stool by RT-PCR on day 13, which was not retested. SARS-CoV-2 was never detected in her respiratory tract samples. She returned home after she was found to have anti-SARS-CoV-2-RBD and anti-SARSCoV-2-NP IgGs on day 29 (see Figure 1).

\section{Discussion}

In this series of patients, 2 had no major gastrointestinal symptoms, while 2 had mild abdominal discomfort and loose stools that resolved spontaneously. These 4 patients were the first set of all the children identified to have mild, loose stools, diarrhoea, and/or their stool viral samples were found to contain SARS-CoV-2 within the first 6 months of COVID-19 outbreak within our regional territory. The HK Government has a strict, statutory reporting and tracking system for several communicable infectious diseases, including COVID-19. By law, these patients were to remain hospitalised and followed by us until they fulfilled the discharge criteria as mandated by the HK Government. We gathered the information of these patients for this case series. Patients 1 and 2 had 42 and 60 days of viral shedding from the enteric tract, respectively. The range of timing that their respiratory sampling had 2 consecutive negative results prior to 2 consecutive sampling from their enteric tracts became negative was wide, which were 4 to 37 days, respectively. Based on literature review and our knowledge, patient 2 had the longest duration of viral shedding from the enteric tract (60 days) and time of negative sampling between respiratory and enteric tracts (37 days) reported in children at the time. ${ }^{[7,8]}$ This prolonged hospitalisation was difficult for him and his father as they were segregated into a single, small room. Patients 3 and 4 were discharged based on measurable anti-SARS-CoV-2RBD IgG, $>10$ days stable condition under observation and $>10$ days from the onset of COVID-19 symptoms or first detectable SARS-CoV-2, the combination of which suggests a low risk of future complications and infectivity in the community. ${ }^{[9]}$ Although in our locality, 4 children suffered from such a predicament, cumulatively from our literature review, the number of children who have prolonged faecal excretion and potential spread of infection of SARS-CoV-2 by this route is approximately $150-200$ in total. ${ }^{[7,8,10-26]}$ Therefore, this issue is a huge concern affecting many patients and deserves further deliberation.

During the first few months of the COVID-19 outbreak, little was known about its incubation period and transmissibility. To protect the community, the management, precaution and isolation measures were mostly drawn from the more well-known predecessors belonging to the SARS-CoV-2 subfamily, including SARS and the Middle East respiratory syndrome (MERS). ${ }^{[27]}$ As such, early in the course of the outbreak and then pandemic, individuals with detectable SARS-CoV-2 in HK were hospitalised and remained under isolation in facilities with a negative pressure air extraction system and double-door design. Patients were allowed to return to the community if clinically stable and had 2 consecutive specimens tested negative for SARS-CoV-2 from their NPS/TS samples (and stool, if previously tested positive), separated by $>24$ hours apart. As more experience and research data about SARS-CoV-2 itself became available, the Centre for Health Protection (CHP) in HK added the presence of anti-SARS-CoV-2-RBD IgG as another qualifier for discharge. ${ }^{[9]}$ The WHO, however, continues to recommend that stable condition and 2 consecutive RT-PCR samples tested negative at least 24 hours apart remain as the criteria for patients to be placed off isolation, in line with the Chinese Centre for Disease Prevention and Control (CDC) and in Singapore. ${ }^{[28]}$ These recommendations differ from those given by the United States CDC, European CDC and Korean CDC. ${ }^{[29]}$ For example, the US CDC recommends that in addition to the above test-based strategy, isolation can be discontinued when $>10$ days have passed since the date of their first positive SARS-CoV-2 test as long as there is no evidence of subsequent illness. ${ }^{[29]}$ In our locality, the most updated, current criteria for release from isolation are: 
1) for symptomatic patients, clinical condition improved, afebrile and either 2 clinical specimens of the same type (such as respiratory or stool) tested negative for nucleic acid of SARS-CoV-2 by RT-PCR taken at least 24 hours apart with 10 days have passed since the onset of illness or detectable neutralizing SARS-CoV-2 IgG antibodies, or;

2) for asymptomatic patients, detectable neutralizing SARSCoV-2 IgG antibodies or 2 clinical specimens of the same type (such as respiratory or stool) tested negative for nucleic acid of SARS-CoV-2 by RT-PCR taken at least 24 hours apart with 5 days have passed since the first positive RT-PCR for SARS-CoV-2.

This policy advocates for testing for neutralizing SARS-CoV$2 \mathrm{IgG}$ antibodies when the late threshold cycle $(\mathrm{Ct})$ values are $>30$. According to a recent study, this protocol is associated with an absence of transmission of viable SARS-CoV-2 viral particles. ${ }^{[30]}$ To further reduce the chance of infection spread, when preparing these patients for release from hospital isolation, we educate them on proper handling of excrements, including cover the lid of toilets prior to flushing and frequent hand hygiene. ${ }^{[31,32]}$

This variability in the guidelines on isolation across different countries and agencies indicate that more scientific investigation and deliberation by our public health officials regarding the optimal infection control measures are desperately needed so that the entire world can overcome this global pandemic with the same line of approach.

In summary, in our cohort of 4 paediatric patients hospitalised due to SARS-CoV-2 detected in their respiratory or stool samples, faecal excretion persisted for many weeks while they only had mild symptoms. Two were discharged after 2 consecutive negative NPS/TS and stool specimens, which required these patients and their caretakers to remain in the hospital for 1-2 months. Two were discharged on the basis that they had circulating anti-SARS-CoV-2-RBD IgGs after a modification in policy was made by the CHP, whereas they would have been mandated to remain hospitalised under isolation in line with the older CHP guidelines and the current recommendations by the WHO and a few other government institutions. As illustrated by our cases and in view of the discrepancies between existing guidelines ${ }^{[29]}$ on the handling of isolation and quarantine of children, family members and other close contacts with COVID-19, a more clear consensus amongst major institutions would facilitate clinicians on enhancing their practice and narrow down the wide diversity and uncertainties in clinical practice. ${ }^{[33]}$ The prolonged excretion of viruses from the stool does not appear to correlate with severity of symptoms, and therefore this method may not be useful for monitoring of disease progression. ${ }^{[34]}$ With more consistency in the guidelines, non-infectious and otherwise healthy children colonized with SARS-CoV-2 may avoid prolonged hospitalization and its associated detrimental effects on physical and psychosocial well-being, and hospitals can retain more reserve in valuable space and resources to support the genuinely needy patients during the COVID-19 pandemic.

\section{AUTHORS' CONTRIBUTION}

Jaime S. Rosa Duque, Phoebe Q. Mak and Joshua S.C. Wong contributed equally to the work and share first authorship. Kelvin K.W. To, Patrick Ip and Mike Y.W. Kwan contributed equally to the work and share corresponding authorship.

\section{Conflicts of InTEREST Disclosure}

The authors declare they have no conflicts of interest.

\section{REFERENCES}

[1] CDC COVID-19 Response Team. Severe outcomes among patients with coronavirus disease 2019 (COVID-19) - United States, February 12-March 16, 2020. Morbidity and Mortality Weekly Report. 2020; 69(12): 343-346. PMid: 32214079. https ://doi.org/10. 15585 /mmwr.mm6912e2

[2] Dong E, Du H, Gardner L. An interactive web-based dashboard to track COVID-19 in real time. Lancet Infect Dis. 2020; 20(5): 533534. https ://doi .org/10.1016/S1473-3099(20)30120-1

[3] Pascarella G, Strumia A, Piliego C, et al. COVID-19 diagnosis and management: a comprehensive review. J Intern Med. 2020. PMid: 32348588. https://doi.org/10.1111/joim.13091

[4] Zhou J, Li C, Liu X, et al. Infection of bat and human intestinal organoids by SARS-CoV-2. Nat Med. 2020. PMid: 32405028. https://doi.org/10.1038/s41591-020-0912-6
[5] Jin X, Lian JS, Hu JH, et al. Epidemiological, clinical and virological characteristics of 74 cases of coronavirus-infected disease 2019 (COVID-19) with gastrointestinal symptoms. Gut. 2020; 69(6): 1002-1009.

[6] Cheung KS, Hung IF, Chan PP, et al. Gastrointestinal manifestations of SARS-CoV-2 infection and virus load in fecal samples from the Hong Kong cohort and systematic review and meta-analysis. Gastroenterology. 2020. PMid: 32251668. https://doi.org/10.105 $3 / j \cdot$ gastro. 2020.03 .065

[7] Xing YH, Ni W, Wu Q, et al. Prolonged viral shedding in feces of pediatric patients with coronavirus disease 2019. J Microbiol Immunol Infect. 2020. PMid: 32276848. https ://doi .org/10.101 $6 / j \cdot j m i i .2020 .03 .021$

[8] Santos VS, Gurgel RQ, Cuevas LE, et al. Prolonged fecal shedding of SARS-CoV-2 in pediatric patients. A quantitative evidence 
synthesis. J Pediatr Gastroenterol Nutr. 2020. PMid: 32452978. https://doi.org/10.1097/MPG.0000000000002798

[9] Scientific Committee on Emerging and Zoonotic Diseases, Centre for Health Protection, Department of Health, et al. Consensus Recommendations on COVID-19 and SARS-CoV-2 made during the meeting held on May 6, 2020.

[10] Jiang X, Luo M, Zou Z, et al. Asymptomatic SARS-CoV-2 infected case with viral detection positive in stool but negative in nasopharyngeal samples lasts for 42 days. J Med Virol. 2020. PMid: 32330309. https://doi.org/10.1002/jmv. 25941

[11] Park JY, Han MS, Park KU, et al. First pediatric case of coronavirus disease 2019 in Korea. J Korean Med Sci. 2020; 35(11): e124. PMid: 32193905. https://doi.org/10.3346/jkms.2020.35.e124

[12] Xiong XL, Wong KK, Chi SQ, et al. Comparative study of the clinical characteristics and epidemiological trend of 244 COVID-19 infected children with or without GI symptoms. Gut. 2020. PMid: 32430348. https://doi.org/10.1136/gutjnl-2020-321486

[13] Tang A, Tong ZD, Wang HL, et al. Detection of novel coronavirus by RT-PCR in stool specimen from asymptomatic child, China. Emerg Infect Dis. 2020; 26(6): 1337-1339. PMid: 32150527. https://doi.org/10.3201/eid2606.200301

[14] Su L, Ma X, Yu H, et al. The different clinical characteristics of corona virus disease cases between children and their families in China - the character of children with COVID-19. Emerg Microbes Infect. 2020; 9(1): 707-713. PMid: 32208917. https: //doi.org/10.1080/22221751.2020.1744483

[15] Zhang T, Cui X, Zhao X, et al. Detectable SARS-CoV-2 viral RNA in feces of three children during recovery period of COVID-19 pneumonia. J Med Virol. 2020; 92(7): 909-914. PMid: 32222992. https://doi.org/10.1002/jmv.25795

[16] Donà D, Minotti C, Costenaro $\mathrm{P}$, et al. Fecal-oral transmission of SARS-CoV-2 in children: is it time to change our approach? Pediatr Infect Dis J. 2020; 39(7): e133-e134. PMid: 32304466. https://doi.org/10.1097/INF.0000000000002704

[17] Mao LJ, Xu J, Xu ZH, et al. A child with household transmitted COVID-19. BMC Infect Dis. 2020; 20(1): 329. PMid: 32381073. https://doi.org/10.1186/s12879-020-05056-w

[18] Wolf GK, Glueck T, Huebner J, et al. Clinical and epidemiological features of a family cluster of symptomatic and asymptomatic severe acute respiratory syndrome coronavirus 2 infection. J Pediatric Infect Dis Soc. 2020; 9(3): 362-365. PMid: 32441753. https://doi.org/10.1093/jpids/piaa060

[19] De Ioris MA, Scarselli A, Ciofi Degli Atti ML, et al. Dynamic viral severe acute respiratory syndrome coronavirus 2 RNA shedding in children: preliminary data and clinical consideration from a Italian regional center. J Pediatric Infect Dis Soc. 2020; 9(3): 366-369. PMid: 32444874. https://doi.org/10.1093/jpids/piaa065

[20] Han MS, Seong MW, Kim N, et al. Viral RNA load in mildly symptomatic and asymptomatic children with COVID-19, Seoul, South Korea. Emerg Infect Dis. 2020; 26(10): 2497-2499. PMid: 32497001 https://doi.org/10.3201/eid2610.202449

[21] Liu P, Cai J, Jia R, et al. Dynamic surveillance of SARS-CoV-2 shedding and neutralizing antibody in children with COVID-19. Emerg Microbes Infect. 2020; 9(1): 1254-1258. PMid: 32515685. https://doi.org/10.1080/22221751.2020.1772677
[22] Du W, Yu J, Liu X, et al. Persistence of SARS-CoV-2 virus RNA in feces: A case series of children. J Infect Public Health. 2020; 13(7): 926-931. PMid: 32546439. https://doi.org/10.1016/j.jiph .2020 .05 .025

[23] Fan H, Yu X, Fu X, et al. Clinical implications of different specimen types for nucleic acid testing in two cases of COVID-19. J Int Med Res. 2020; 48(8): 300060520949067. PMid: 32840148. https://doi.org/10.1177/0300060520949067

[24] Wang X, Zheng J, Guo L, et al. Fecal viral shedding in COVID19 patients: Clinical significance, viral load dynamics and survival analysis. Virus Res. 2020; 289: 198147. PMid: 32866537. https://doi.org/10.1016/j.virusres. 2020.198147

[25] Xie J, Long X, Ren C, et al. Follow-up study of long-time positive RT-PCR in stool specimens from asymptomatic children infected with SARS-CoV-2. Pediatr Infect Dis J. 2020; 39(10): e315e317. PMid: 32932332. https://doi.org/10.1097/INF.0000 000000002837

[26] Cho SM, Ha GY. A case of COVID-19 in a 45-day-old infant with persistent fecal virus shedding for more than 12 weeks. Yonsei Med J. 2020; 61(10): 901-903. PMid: 32975066. https ://doi.org/10 $.3349 / \mathrm{ymj}$. 2020.61.10.901

[27] Kwan YW, Leung CW, Chiu MC. Diarrhoea as the presenting sign in an adolescent suffering from severe acute respiratory syndrome. Eur J Pediatr. 2005; 164(4): 227-30. PMid: 15645282. https://doi.org/10.1007/s00431-004-1618-3

[28] World Health Organization. Clinical management of severe acute respiratory infection (SARI) when COVID-19 disease is suspected: interim guidance. 13 March 2020. https://doi .org/10.15557 /PiMR. 2020.0003

[29] European Centre for Disease Prevention and Control. Guidance for discharge and ending isolation in the context of widespread community transmission of COVID-19-first update. 8 April 2020.

[30] Laferl H, Kelani H, Seitz T, et al. An approach to lifting self-isolation for health care workers with prolonged shedding of SARS-CoV-2 RNA. Infection. 2020; 1-7. https ://doi .org/10.1007/s15010 -020-01530-4

[31] McDermott CV, Alicic RZ, Harden N, et al. Put a lid on it: are faecal bio-aerosols a route of transmission for SARS-CoV-2? J Hosp Infect. 2020; 105(3): 397-398. PMid: 32315667. https: //doi.org/10.1016/j.jhin.2020.04.024

[32] Kampf G, Brüggemann Y, Kaba HEJ, et al. Potential sources, modes of transmission and effectiveness of prevention measures against SARS-CoV-2. J Hosp Infect. 2020. https ://doi . org/10.1016/ j.jhin.2020.09.022

[33] Loades ME, Chatburn E, Higson-Sweeney N, et al. The Impact of social isolation and loneliness on the mental health of children and adolescents in the context of COVID-19. J Am Acad Child Adolesc Psychiatry. 2020. PMid: 32504808. https://doi.org/10.1016/ j.jaac. 2020.05.009

[34] Zuo T, Liu Q, Zhang F, et al. Depicting SARS-CoV-2 faecal viral activity in association with gut microbiota composition in patients with COVID-19. Gut. 2020. PMid: 32690600. https ://doi .org/ 10.1136/gutjnl-2020-322294 